\title{
Monitoring the oxygen level in the Szarvas-Kákafok Deadarm
}

\author{
Gábor Csizmarik ${ }^{1}$ - Ferenc Ligetvári² ${ }^{2}$ Csaba Juhász ${ }^{3}$ - Péter Simándi ${ }^{1}$ \\ ${ }^{1}$ Faculty of Water- and Environmental Management, Szent István University, H-5540 Szarvas, Hungary \\ ${ }^{2}$ Faculty of Agricultural and Environmental Sciences, Szent István University, H-2100 Gödöllő, Hungary \\ ${ }^{3}$ Department of Water- and Environmental Management, University of Debrecen, H-4023 Debrecen, Hungary \\ csizmarikg@gmail.com
}

Keywords: deadarm, water quality, oxygen variation, $p H$ rise

SUMMARY

The water quality of the Szarvas-Békésszentandrás Dead Körös is generally meso-eutrophic, and meso-saprobic. However, particularly under higher temperature conditions, the water body may change toward the eutrophic state, even algal blooms could be observed previously.

The present measurements were conducted during a two week period, twice a day. Three water samples were taken horizontally, from the surface, bottom and the middle of the water body. The samples were examined in situ. The oxygen content, the temperature, the pH and the conductivity were measured by potentiometric methods.

Increasing $\mathrm{pH}$ was detected in correlation to the temperature, which indicated a rising photosynthetic activity. Also, the $\mathrm{O}_{2}$ concentration showed high variations, especially, when the fresh water supply from the river was stopped, due to a small flood in the river Körös.

These results indicate the increasing eutrophication processes in the deadarm, and the high load and instability of the ecosystem.

\section{INTRODUCTION}

The Szarvas-Békésszentandrás Holt Körös (“Kákafok Deadarm”) is the biggest deadarm of Hungary. Its basin area is $927 \mathrm{~km}^{2}$. The overall length is $29.2 \mathrm{~km}$, the average width is $71 \mathrm{~m}$, the surface area is 207 ha, the average water depth is $2.2 \mathrm{~m}$, and the water quantity is 4.5 million $\mathrm{m}^{3}$. The water quality is generally mesoeutrophic, and meso-saprobic (Pálfai, 2001).

The oxbow-lake has multiple utilizations. The most significant utilization is agricultural: The water is used for fish culture, for irrigation and for inland water reservoir as well. Also, it has an important role, as a diversion reservoir. Finally, the oxbow-lake has a significant recreational role. However, particularly under higher temperature conditions, the water quality changes toward the eutrophic state, even algal and macrophyte bloom could be observed.

In order to preserve the water quality, the deadarm has continuous water supply from the river Körös.

The European Union Water Framework Directive states that the surface and groundwater bodies should achieve good status by 2015. Therefore, monitoring the water quality is an important task. The potentiometric measurements give us quick and continuous monitoring possibilities in the field. The oxygen line, the $\mathrm{pH}$ and the conductivity variations in the water body indicate the quick response of the ecosystem to the environmental influences. Our goal was, to follow the immediate responses, and therefore, to estimate the ecological state of the deadarm.

\section{MATERIALS AND METHODS}

\section{Sampling}

The measurements have been conducted in 2010 for two weeks, twice a day; in the morning and in evening.

The samples were taken by a one liter measuring flask with length marks.

Three water samples were collected horizontally, from the littoral zone, from the mid section, and from the centre line of the deadarm. The depths of the water body were $1 \mathrm{~m}, 2.4 \mathrm{~m}$ and $4 \mathrm{~m}$. From the littoral zone the samples were collected from the surface and the bottom water body, while surface, middle part and bottom water samples were collected from the mid section and the centre line of the deadarm. The samples were measured immediately after the sampling in the flask, in order to obtain in situ data.

\section{Experimental methods}

The oxygen content was measured by a WTW OXI 330 oxygen meter.

The $\mathrm{pH}$ was recorded with a THERMO ORION 3STAR $\mathrm{pH}$ meter.

The temperature and the conductivity was followed by a TOA CM-21P conductivity meter 
The meteorological temperature data were obtained from the Szarvas meteorological station.

\section{RESULTS AND DISCUSSION}

\section{Variation of the temperature}

During the measurement period diverse weather conditions were detected. The daily average temperature and its standard variation was calculated (Figure 1). The lowest temperature was on $25^{\text {th }}$ July, and the highest was on $4^{\text {th }}$ August. The air temperature showed high daily variations, which are indicated by the high STD values. The changes in the water body were more balanced, however the highest temperature reached $27.1^{\circ} \mathrm{C}$. The low STD values indicate, that thermocline has not formed, even in the $4 \mathrm{~m}$ deep centre line section. Therefore, the oxbowlake can be classified as shallow lake (Water Framework Directive, 2000).

Figure 1: Comparison of the daily average temperature of the air and water body. The bars indicate the standard deviation.

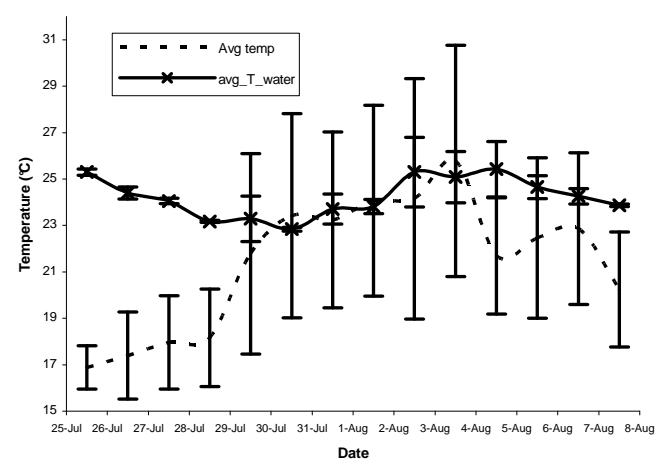

\section{Variation of the conductivity}

The conductivity did not showed significant variations, the average values remained between 40.2 and 50,1 $\mathrm{mS} / \mathrm{m}$. Also, the standard deviations remained below 1.30. The small decrease can be explained with the water refreshment from the river Körös (Figure 2).

Figure 2: The changes in the average conductivity, compared to the water temperature. The Ec showed the effect of the external water refreshing.

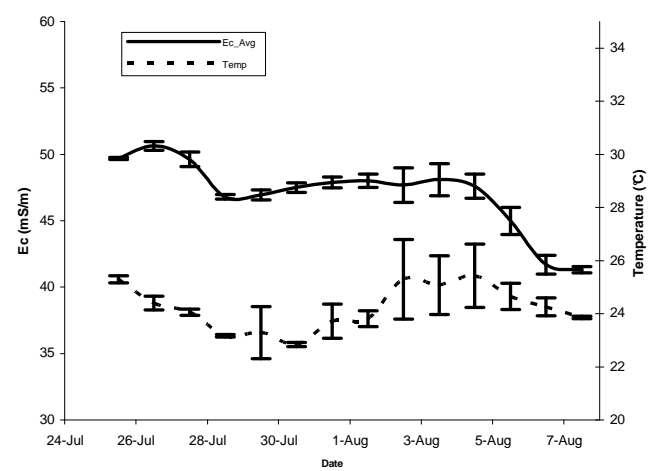

\section{Variation of pH}

At a previous observation in 2008 , extreme high $\mathrm{pH}$ was detected, which reached the 10.3 value. The present measurements support its possibility. As the water temperature started to rise, it led to an increasing photosynthesis, which lowered the $\mathrm{CO}_{2}$ and $\mathrm{HCO}_{3}{ }^{-}$content of the water. Eventually it was showed in an increased pH (Figure 3). These results are well correlated with the observation of Schwoerbel (1999), who measured daily variations with $\mathrm{pH} 9$ peak in mountain springs. 
Figure 3: The changes in the average $\mathrm{pH}$, compared to the water temperature. The variations of $\mathrm{pH}$ followed the temperature changes.

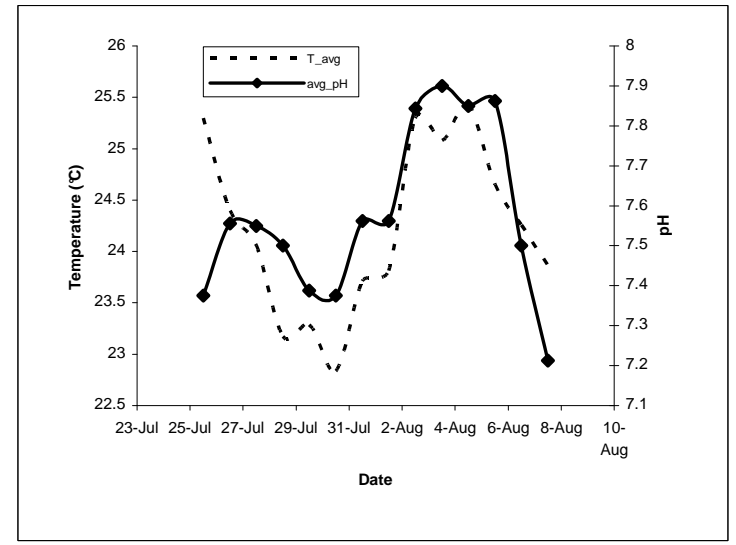

\section{Variation of the oxygen content}

Although the deadarm is continuously supplied by fresh water from the river Körös, under extreme circumstances it could be stopped. Due to a smaller flood on the river the deadarm was closed between $30^{\text {th }}$ July and $3^{\text {rd }}$ August. As the very slow stream stopped, it dramatically changed the oxygen relations in the water body.

In the littoral zone the oxygen content increased due to a photosynthetic activity and a still water. However the diffusion in the $1 \mathrm{~m}$ water body was able to supply sufficient $\mathrm{O}_{2}$ in the bottom layer (Figure 4).

Figure 4: Changes of the average $\mathrm{O}_{2}$ in the littoral zone, compared to the water temperature. The oxygen variation was similar in the surface and bottom layer, and followed the temperature changes

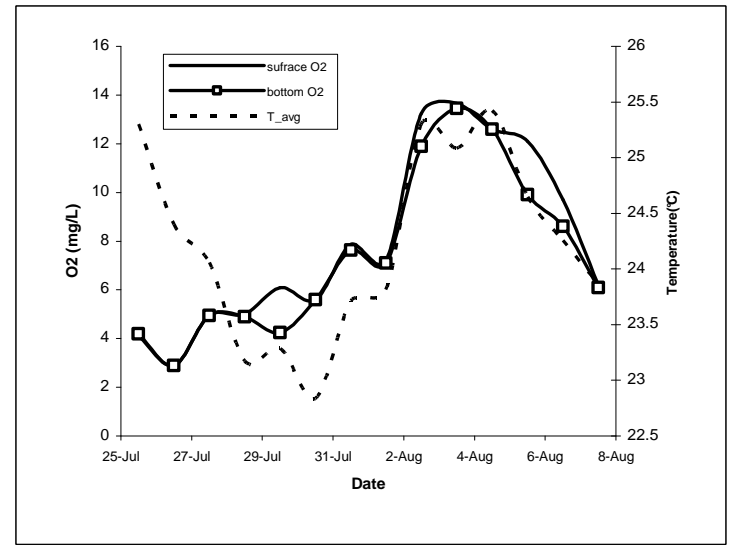

In the mid section the water was $2.4 \mathrm{~m}$ deep. While the constant stream supported sufficient mixing effect, in the still water oxygen stratification started with the higher temperatures and higher photosynthesis (Figure 5). After the flood, the oxygen content decreased, but was more balanced in all depth.

Figure 5: Changes of the average $\mathbf{O}_{2}$ in the mid section, compared to the water temperature. 


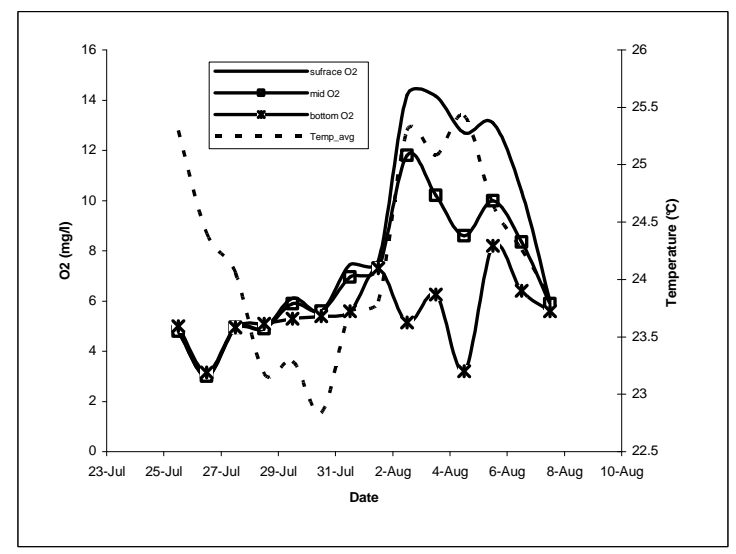

In the deepest centre line region the changes were more dramatic. On the surface the $\mathrm{O}_{2}$ level reached the $18.2 \mathrm{mg} / \mathrm{l}$ value, while in the bottom layer decreased to $1 \mathrm{mg} / \mathrm{l}$ (Figure 6). After the water supply the $\mathrm{O}_{2}$ content remained at $5 \mathrm{mg} / \mathrm{l}$ level.

Figure 6: Changes of the average $\mathrm{O}_{2}$ in the centre line of the deadarm, compared to the water temperature.

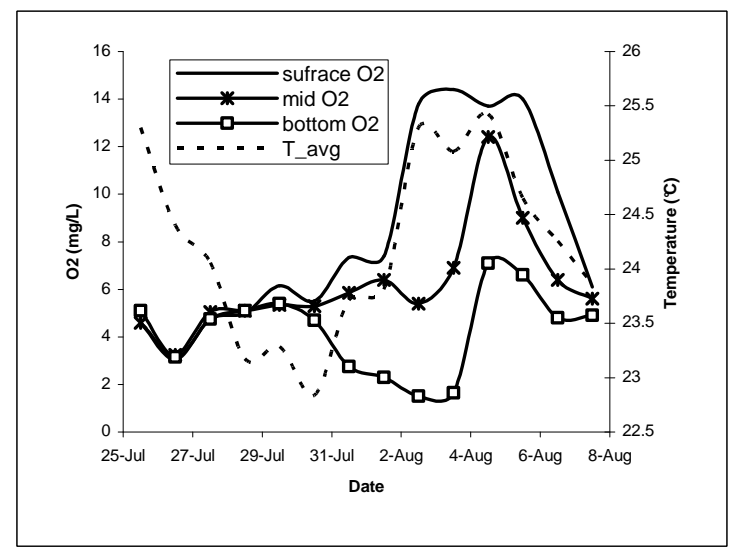

Summarized, these results indicates that the Szarvas Kákafok oxbow-lake ecosystem became highly instable, which may indicate the overload of the water body. Kud-Hansen et al. (1998) states, that in the fish ponds the oxygen content does not decreases below $3 \mathrm{mg} / \mathrm{l}$, if the organic matter production is autochtonous. However, if the temperature rises for a longer period in the deadarm, the variation of the $\mathrm{pH}$ and the oxygen content may reach extreme conditions. The $1 \mathrm{mg} / \mathrm{l}$ concentration could be dangerous for the higher organisms (Horváth, 2000). These results also indicate the advanced eutrophication state of the deadarm. The continuous water supply from the living river is essential for the health of the water body. However, in long term circumstances, the nutrient load should be effectively decreased

\section{REFERENCES}

Directive 2000/60/EC of the European Parliament and of the Council of 23 October 2000, establishing a framework for Community action in the field of water policy (2000)

Horváth L. (ed.) (2000): Fish biology and fish culture (in Hungarian). Mezőgazda Kiadó, Budapest

Knud-Hansen, C.F. (1998). Pond Fertilization: Ecological approach and practical applications. In: McElwee et al. (ed.). The Pond Dynamics/Aquaculture Collaborative Research Support Program, Oregon State University, Corvallis, Oregon. p. 40.

Pálfai, I. (2001): Oxbow-lakes in Hungary (in Hungarian). Ministry for Transport, Communication and Water, 155-156.

Schwoerbel, J. (1999): Einführung in die Limnologie. Gustav Fischer, Jena 456. 